\title{
Interpreting and presenting marginalized voices through intersubjective accounts
}

\section{Introduction}

There is an ongoing challenge for social science researchers to interpret and present issues concerning the lives of research participants who are embedded in specific contextual situations, into which the researcher enters as an outsider. The challenges increase when seeking to give voice to those considered marginalized in particular socio-political contexts, and where the use of translation from one language to another is required (Littig and Pöchhacker, 2014). This often involves three parties in the process of the generation of data: researcher, interpreters, and research participants. It is recognized that the body of literature discussing issues of working with interpreters in social science research is light (Edwards, 1998; Temple and Edwards, 2002; Temple and Young, 2004). This paper adds to literature by exploring matters of intersubjectivity, positionality and representation, recognising limitations associated with using interpreters, and highlighting positive contributions from the use of three parties in the generation of qualitative research material.

The paper focusses on experience from $\mathrm{PhD}$ research that sought to capture and present voices that were considered marginalized in the context where the research was conducted. Emphasis is placed upon the positionality of those involved in the production of data, and reflections on power relations, translations, and representations in the construction of interpreted lives of others. The research explored community empowerment impacts and interpreted lived experiences of a Fairtrade certified sugar scheme in Malawi. For that people-centred development research it became important to give voice to those often marginalized from interactions and discourse related to the case study. Listening to these voices opened possibilities to present issues concerning the lives of individuals, and potentially lessons for other Fair Trade schemes.

\section{Fair Trade Community Empowerment Research ${ }^{1}$}

Fair Trade has been central as part of an expanding movement to connect markets and consumers in the global north with commodity producers in the global south. The Fair Trade approach highlights perceived problems in trade such as exploitation, marginalization, and exclusion from benefits of global market participation. Fair Trade discourse and practice have an emphasis on people-centred development, with a focus on efforts to empower producers and

\footnotetext{
${ }^{1}$ The research was conducted for a PhD Studentship supported by collaboration between Newcastle University and Traidcraft Plc, funded by the ESRC, using empirical material obtained from research of a Fairtrade certified sugar producer organization in Malawi, Kasinthula Cane Growers Limited (KCGL). The producer certification and product labelling system "Fairtrade” is governed by Fairtrade Labelling Organizations International (FLO) and its members. For some introduction and background on Fair Trade see FLO, 2009; Nelson and Pound, 2009; Raynolds et al, 2007.
} 
their communities. Despite increased use of the terms community and empowerment in Fair Trade literature and marketing, at the time of this research there had been little work to understand their meaning critically in the context of Fair Trade.

Low-income producer groups are often treated as conduits of community empowerment approaches and are generally assumed to be willing and able to share benefits of Fair Trade among producer members and a wider community. To contribute to a developing academic critique and to challenge such assumptions, this research explored governance and institutional factors that influence particular social and political relations in a specific context. It analysed inequalities, hierarchies, dependencies, and intended and unintended Fairtrade outcomes to provide an opportunity to reflect on how Fair Trade can continue to learn and evolve to improve livelihoods of a wider population of producers. Insights were obtained through analysis of the experiences of all actors involved in the production of sugar cane in this case study (principally farmers and hired labour).

In order to elicit such knowledge, a methodology was developed to both conceptually and practically hear voices of all involved in the sugar cane production process in the selected case study. The next section discusses approaches and considerations regarding the use of three parties in multilingual research. This is followed by a presentation of how this research drew on insights from grounded theory and postcolonial theory to interpret lived experiences of others as intersubjective accounts, and a discussion of challenges to mitigate such as bias, power relations, and representation.

\section{Triple subjectivity and three-way production of data}

While literature exists (Edwards, 1998; Freed, 1988; Temple and Edwards, 2002; Temple and Young, 2004; Williamson et al, 2011), overall the literature on working with interpreters or translators is light. In response to a highlighted gap in literature regarding 'detailed descriptions about and critical reflection on the methods used in interpreter-facilitated cross-language interviews' (Williamson et al, 2011: 385), the authors argue that an interpreter-facilitated approach can be an effective alternative to translation practices. In other words, involving a third party as an active participant (interpreter) in the collection of data, translating during interviews, could provide interpretations that more closely reflect the lives of others compared to more passive post-interview translation of transcripts. This approach, however, introduces challenges related to intersubjectivity, positionality and representation.

In international development research, researchers often rely on translators who work with written materials to convert from one language to another (Baker, 1981), and interpreters who convert spoken material from one language to another, translating back and forth, requiring interpersonal skills. Such reliance is particularly crucial when there is a wish to hear 
perspectives of the most silenced in society (Edwards, 1998). Joining the researcher and participants, interpreters represent a further filter of knowledge guided by their positionalities.

All researchers have a role in the process of interpretation and documentation (Bondy, 2012; Shklarov, 2007). The research process becomes subject to what Temple \& Edwards (2002: 6) term 'triple subjectivity'. The use of the 'third person' has also been discussed by Edwards (1998) and Murray \& Wynne (2001:165) who summarize this as a process of the three-way production of data (researcher, participant, and interpreter). As active producers of research data, interpreters (for example a research assistant) should not be considered passive participants (Fathi, 2013); rather they bring their own values, experiences, and assumptions that shape their interpretation (Temple and Edwards, 2002; Temple and Young, 2004). Their role is not to solely provide verbatim translations (Squires, 2009), but with varying degrees of freedom, 'contribute, direct and shape production of knowledge' (Williamson et al., 2011: 383; Littig and Pöchhacker, 2014), helping to create knowledge derived from triple subjectivity.

Recognising the role of interpreters and a researcher's dependence upon them, Edwards (1998: 206) puts forward 'a reflexive model of working with interpreters that does not conceal the politics of the research process'. She argues that by stressing 'working with' rather than 'using' interpreters, they become more visible as active participants, not just passive devices to translate. The goal, as discussed by Murray and Wynne (2001), Squires (2009), and Williamson et al (2011) is for the interpreter to achieve 'conceptual equivalence' (Williamson et al, 2011: 384), in other words, remain as close as possible to the participants words, meanings, and messages, excluding the interpreters' views and not omitting messages that the interpreter might think are not relevant or of interest.

When working with research in a second language the principal researcher will only receive a second hand interpretation and data generated from a three-way production process. To be as confident as possible that the data generated closely reflects the actual views and messages of participants it is important to incorporate additional methodological steps to provide further validation and clarification. In such instances it becomes important to acknowledge how the participation of interpreters affects the nature of the material collected by reflecting on intersubjectivity, positionality and representation.

\section{Interpreting lived experiences as intersubjective accounts}

When social science research involves participation, relationships, and conversations between people of various cultures, engagement between participants generates intersubjective accounts. The term intersubjective refers to the construction of shared meanings of everyday life derived from interactions between people (Seale, 2012). Through ongoing dialogue, perspectives of the researcher and the researched are heard alongside one another, working together to construct meaning (Baxter and Eyles, 1997; Seale, 2012). Those accounts produce 
divergent, intersubjective 'truths' or multiple versions of 'truths' of an event or phenomena (Crang and Cook, 2007; Pain, 2001) that reflect different partial and situated knowledges. For the researcher this presents a series of methodological challenges to mitigate which increase with the use of third parties as interpreters as active participants in the construction of data.

The lived experiences of others can be understood as an interpreted understanding of the social world of others. Empirical material with which to construct such an understanding is most commonly obtained using qualitative research methods. Within this strand of human geography that draws upon ethnographic methodologies and phenomenological perspectives of lived experiences, 'emphasis is placed on developing 'grounded theories' from careful local studies characterized by participant observation and an understanding of the lifeworlds of the researched' (Limb and Dwyer, 2001: 4). The principal ideas from grounded theory were incorporated into this research to enable the voices of those being researched to shape key understandings of lived experiences, with recognition that those voices are embedded in context (Fathi, 2013). Employing some of the guidelines of grounded theory generates understandable and meaningful contributions for both academic and practitioner partners interested in the consequences of people-centred approaches on the lives of others.

The second theoretical approach utilized was postcolonial theory. A critical postcolonial reflection contributes towards a more grounded interpretation in the following three ways. First, by providing a space to critique imaginations of communities (Mohan, 2001) and destabilize those constructions (Mercer et al., 2003), a postcolonial lens can 'un-mask' and account for complexities of social and political relations in a place in which low income smallscale producers are embedded. Malawi, where this research was conducted, is defined as postcolonial, recognising continued legacies that shape the lives of those embedded in a postcolonial context (at one time under colonial rule). Malawi came under British rule in 1891, and with this rule came the imposition of British designed political, social, and economic policies. Among the legacies of the colonial period (that has continued in the postcolonial state) is the imposition and embedding of a modern state political system into a country that has embedded hierarchical communal societies, and dependence on export income from the production of agricultural cash crops on large estates (especially tobacco, tea, and sugar). Increased visibility of the postcolonial geography helps to facilitate the generation of themes to provide an understanding of grounded realities, underlying processes, and lived experiences of research participants.

Second, using a postcolonial lens methodologically necessitates giving voice and identity to all, including subordinated (subaltern) peoples (Hoogvelt, 1997: 158). In other words it includes both those normally consulted for views and participation in research and those often 
marginalized. ${ }^{2}$ Understanding the positions from which people speak, who actually speaks, for whom, and under what conditions helps to obtain a richer knowledge of livelihoods, needs, and priorities.

A third reason for the incorporation of a postcolonial reflection is to raise issues of representations of others and reflexivity in research. Scholars have noted the contributions of a postcolonial reflection in deconstructing representations (Spivak, 1988), highlighting the problems of speaking for others (McEwan, 2008), and acknowledging power relations in representations and research, including inequalities between the researcher and the researched (Kindon et al., 2007; Mohan, 1999; Mercer et al., 2003; Power, 2003; Raghuram and Madge, 2006). Kindon et al. (2007) highlight the danger of re-enforcing pre-existing power hierarchies by only presenting elite local knowledge. Furthermore, there is a potential that some participants may feel they are the 'subjects' as the question and answer format of interviewing may reproduce relations of authority (Narin et al., 2005).

There are a number of noted challenges regarding interpretation and presentation of intersubjective accounts related to positionality including bias, power relations, and representation. From whatever background, all researchers face these challenges when entering the lifeworlds of identified populations. Certain biases are formed from upbringing, cultural surroundings, geographical location, and experiences. To help mitigate the effects of bias, Baxter and Eyles (1997: 514) use the term 'disciplined subjectivity' as 'being mindful of one's own ethnocentricity and biases' as a positioned subject. Positioning oneself in relation to a particular set of beliefs and views of the world is the key to grounding knowledge in a specific intersubjective context (Haraway, 1988; Moser, 2008). Raghuram and Madge (2006) argue, therefore, that it is necessary to acknowledge bias and be open to recognising positions of other research participants. Working in a process of three-way production of data, it is necessary to recognise the positionalities (such as ethnicity, nationality, gender, age) of the principal researcher, research assistants, and participants (Rose, 1997; Skelton, 2001), but also to consider the changing nature of positionalities as different research relationships develop.

Expanding on the issue of subjectivity, with reference to Spivak (1988) and Townsend (1995), translation is part of the process of (re)constructing representations of others. The research process is imbued with issues of (unequal) power relations and intersubjective factors and cross-cultural translation from one context to another. When social research works with interpreters (or translators), the potential for biases or misunderstandings increases (Fontana and Frey, 2008).

\footnotetext{
2 The term subaltern refers to those viewed as subordinated or worse off in society, adopted by postcolonial writers such as Guha (1982) and Spivak (1988).
} 
Discussing the task of presenting and disseminating qualitative material collected, in deconstructing development discourse Munck (1999: 204) promotes an 'engagement that does not presume to speak for others authoritatively'. In that spirit, it is important to acknowledge bias and an inability to completely represent others. The best one can expect to do, as Cook and Crang (1995) discuss, is to use a combination of emic (participant accounts) and etic (researcher accounts) given the impossibility of being one hundred percent emic. In fact, as Ergun and Erdemir (2010) note, it is important to not lose the value of etic insights as the principal researcher promotes what he or she considers to be the most important insights from their position. In this research, working with research assistants, it was important to incorporate their interpretations and opinions as active participants (Edwards, 1998). By emphasising interpretation, this recognises the influence of researchers' perspectives and that any presentation can only be an interpretation.

\section{Accessing marginalized voices}

Initial contact points for this research were supplied by Traidcraft and other Fair Trade personnel. ${ }^{3}$ These contacts represented both the key informants to obtain access to further potential participants and the elite nodes in the local sugar producing districts. From a postcolonial methodology perspective, such 'local elites' represent what Spivak (1999) terms 'native informants', who are traditionally the people external agents come into contact with (also often referred to as gatekeepers, Bondy, 2012). These positions can generate perceptions of superior levels of control and influence within a community. Such stratification conflicts with imaginations of equality in co-operative producer groups embedded in people-centred community empowerment discourse (Lacey, 2009). For this research it was important to gain access to those not regarded as local elite to enable more people in the Kasinthula producer community to have their perspectives heard as informants in the research.

Research participant selection was based on established contacts and from networks of those contacts to identify participants. From identified populations a sample frame of research participants was selected, from which samples were taken, stratified by age, gender, and occupation. Once samples were established a combination of methods were used in this research. In total, 47 one-to-one interviews were conducted with sugar farmers; 55 one-to-one interviews with sugar employees; 11 focus group discussions with committees, farmers, and employees; 8 group discussions with villagers living in a sugar scheme community; interviews with members of the Kasinthula management team; interviews with local District Assembly representatives; and 2 diaries from 2 employees to capture narratives of lived experiences.

\footnotetext{
${ }^{3}$ Traidcraft is a UK-based Fair Trade Organisation that buys and sells Fair Trade goods. It also participates in development projects, for instance assisting Kasinthula Cane Growers achieve Fairtrade certification status.
} 
Before organising pilot interviews, a draft semi-structured questionnaire was constructed to allow the possibility of drawing out sensitive information on relations with others, impacts, and responses to shocks that may affect livelihoods. In this research, consistent with both grounded theory and providing space for subaltern perspectives, the semi-structured questionnaire included open-ended questions that enabled participants to answer in their own terms (Bryman, 2008; Flick, 2009), providing spontaneous and nuanced feedback to such questioning. The quality of the feedback received was heightened by re-confirming understanding of any questions that were unclear.

As part of that process a research assistant was recruited to conduct interviews at Kasinthula Cane Growers Limited (KCGL) in Chichewa (the participants' first language). In order to provide space for voices to be heard through a conversational interview process it was necessary to seek some research assistance as the majority of research participants did not share sufficient common language with the principal researcher to conduct such an interview. Recruiting bilingual research assistants (RAs) is common practice (Hyman et al, 2008; Knight et al, 2009; Williamson et al, 2011) to help to 'bridge the linguistic and cultural divide between researcher and participant' (Murray and Wynne, 2001:158). Also, interviewers sharing the same nationality as the participants may receive greater authority due to the greater familiarity (Edwards, 1998). However, this final point is increasingly contested. Assumptions that similarities such as nationality 'guarantee' authority and insider status may be misleading as there will also be differences between those sharing some of the same traits (Valentine, 2002; Ergun \& Erdemir, 2010). Moreover, a principal researcher as an 'outsider' may gain respect and develop rapport due to their professional status (Ergun \& Erdemir, 2010).

In this research, assistants were recruited not purely on the basis of sharing the same nationality, but importantly their professional status and field experiences (Littig and Pöchhacker, 2014) which helped to develop rapport and respect with participants. Along with the principal researcher, assistants were seen as professional researchers with relevant knowledge, and to be trusted to listen to voices of participants and develop messages to be disseminated to a broader audience. This was helped by explaining as clearly as possible that the purpose of the research was to generate new knowledge to inform broader debates and changes regarding Fairtrade standards and activities of those in the Fair Trade movement.

The importance of finding and employing researchers with qualitative research and language proficiency has been well noted (Adamson and Donovan, 2002; Murray and Wynne, 2001). In the first instance, a graduate of the University of Malawi in Zomba was recruited, RA\#1, who had experience of working for consultants on international development research projects and, therefore, possessed valuable skills and knowledge of interviewing people in low income districts of Malawi. As a graduate with this experience the RA possessed a position of authority which in practice was respected throughout our engagements with research participants. 
Associated effective interpersonal and communication skills helped to garner positive relations and aided in collecting richer material.

Caution should be applied when working with assistants in the interview process as misunderstandings or misinterpretations may arise. To help overcome such concerns the RA was inducted into the research by explaining the background, aims, and nuanced aspects of the project. As part of this best practice proposed by Edwards (1998) there was agreement on the confidential nature of the interviews, respective roles, and parameters for the work such as rates of pay and other conditions including travel and accommodation costs.

All of the pilot interviews were conducted by the principal researcher and the research assistant to get first-hand experience of how the interviews and pilot questionnaire were being received. RA\#1 asked questions and translated summaries of the responses as the interviews progressed. At the end of each interview a consultation was conducted to make amendments in light of experience and drew upon the RA's experience of conducting village based research. On a number of occasions participants viewed the principal researcher as someone positioned to facilitate immediate change, with links to more funding, and who could liaise in local sociopolitical disputes by taking messages from one party to another. This follows dilemmas of cross-cultural research highlighted by Edwards (1998), Herod (1999), and Skelton (2001) that outsiderness and whiteness affect ways in which participants view and respond to a researcher. In response to such messages, the purpose, and therefore the limitations, of what could be promised were re-iterated. It was also emphasized that voices of all participants would be represented in research dissemination.

By conducting the pilot interviews, those being interviewed were allowed to participate in the research and questionnaire design by using what they said to determine the focus of the research and remaining material collection. After completing the pilot interviews all of the responses collected were reviewed to look for interesting issues and themes emerging to guide the design of interview schedules and questionnaires for interviewing larger numbers of participants. Therefore, the participant material from the pilot interviews drove the final questionnaire design and the potential answer options.

Additional graduates of the University of Malawi (two male and two female RAs) with relevant fieldwork experience were recruited to form a research team. The new RAs were provided with a comprehensive background to the project, the pilot work completed, and agreed strategies and ethics as part of good preparation practice in interpreter-facilitated research (Adamson and Donovan, 2002; Freed, 1988; Murray and Wynne, 2001; Squires, 2009; Williamson et al, 2011). At the beginning of each round of interviews an RA explained how the session would proceed and reminded people why they had been called for interview at Kasinthula's offices. As with the pilot interview process, the objective was to avoid taking up too much time of the 
participants. Furthermore, it was important to establish a good rapport between researchers and participants to increase trust and openness (Adamson and Donovan, 2002; Reeves, 2010; Williamson et al., 2011).

Referring to issues of triple subjectivity and making assistants visible (Edwards, 1998), the interview format was one-to-one, representing a fairer power balance in interviews and enhancing the authority of the assistant conducting the interview. The principal researcher joined in the interviews on occasion to answer any questions that the interviewers felt unable to answer, or were specifically directed at the principal researcher to answer.

Through the process of conducting research many sugar cane employees (subalterns) raised pertinent issues and themes from open questions that had not been raised in other interviews. For instance one man who volunteered some time for interview after working all day cutting cane stated:

'we only know about Fair Trade because of your meeting yesterday, you are the first to tell us anything about Fair Trade. Before my friends and I had heard the term but did not know much about it'

In response to such statements the research team agreed to return to the employee camp to have a discussion with whoever would be available then for a group discussion. A revised interview schedule was constructed to elicit issues that the seasonal employees wanted to raise, ensuring participants were active in the research process, and marginalized voices were captured.

Given the circumstances of this situation, this was a particular point to reflect upon the positionality of a researcher as an outsider visiting this producer community. It was clear that the seasonal employees felt excluded from the majority of processes connected to KCGL, including the visits of Fair Trade and other buyers. It was, therefore, important to make sure that an opportunity was provided to voice their opinions in as safe an environment as possible, hence the agreement to meet again at the employee camp. Such marginalized voices wouldn't have been heard without the employment of suitable and well-briefed RAs.

Focus group discussions captured intersubjective (multiple perspective) accounts from different categories of producer at KCGL, aided by the use of audio recording technology. In selecting moderators for the discussions, criteria of gender and different strengths and skill sets of assistants were incorporated (Edwards, 1998). In Chichewa one assistant conducted the introductions, moderated, and used a digital recorder, another took notes of the conversations in English and interrupted at relevant points to probe further. The process of mixed gender teamwork to interview, probe, record, and cross-check helped to enhance confidence in validity of the data and achieve the best possible conceptual equivalence, within the limitations of available resources. Consistent with postcolonial reflection, the process of probing further 
integrated the researchers into the research (Temple and Edwards, 2002), minimized the risk of stereotyping (Shklarov, 2007), and helped to 'un-mask' the diversity of actors and social and political relations.

From that process, two employee members of a Fair Trade committee at Kasinthula were asked if they would be willing to write about their experiences. The employees had approached the research team to request a separate interview as they felt their position did not enable them to voice their opinions with the wider group present. Echoing Spivak (1999) in this approach, those normally subordinated became the native informants, which was in contrast with other occasions when the most influential sugar farmers represented the native informants to visitors and auditors. The employees consented to a proposal to keep diary records and later returned their transcripts charting their experiences. This also contributed to a triangulation process of conducting interviews (one to one personal perspectives), focus group discussions (intersubjective accounts), and diaries (life stories or narratives).

\section{Discussion}

Obtaining empirical research material using third parties will inevitably incur some data loss and possible misinterpretations. However, recognising limitations associated with crosscultural research, the active participation of research assistants and participants in the design and outputs of qualitative research can provide useful, unique approaches and insights. In this research this was particularly exemplified with the example of interviewing sugar cane employees.

Looking at the population of the Kasinthula sugar cane organisation through a postcolonial lens revealed multiple layers of producer, all experiencing different levels of governance, participation, and wealth capture. With the use of research assistants it was possible to incorporate voices of sugar cane employees who, until this research, had not been consulted by 'outsiders' visiting the scheme. Moreover, the interactions between the three parties led to the exposure of unique findings regarding the varied lived experiences of Fair Trade at Kasinthula, and the development of additional methodological steps to capture marginalized voices (in particular through group discussions at the employee camp and the use of diaries).

Working with research assistants brought additional insights that a sole researcher would not have captured. In addition to providing functional language translation deliverables, research assistants were able to put forward their perspectives and insights on the research, in particular the reactions of participants, through daily research team briefing meetings. Once interviews were completed, outputs were collated at the end of the day, enabling all researchers to check and validate data to ensure the interpreted and translated material was clear and understood to facilitate analysis, and discuss what was being said to capture the mood, key points of interest, and as much of the spoken content as possible. In the case of group discussions, after each 
discussion research assistants translated and transcribed what was said by listening to the recorded discussions. Any material not captured in writing during the interview was incorporated into the final transcripts through this process.

Emphasising interpretation recognizes the influence of multiple researchers' impressions and positionalities, and therefore that any presentation can be no more than an interpretation that is shaped by triple subjectivity. Ultimately the principal researcher is in the position to decide what perspectives of participants and interpreted themes and observations to foreground in the final presentation of research. An important responsibility is to be mindful of how the data was collected and ensuring voices of all are presented when that is central to the research objective.

\section{Conclusion}

Acknowledging challenges related to cross-language interpreter-facilitated field research, this paper has presented a methodology that weaved together insights from three key areas of literature (postcolonial theory, grounded theory, and literature on triple subjectivity) to add to a recognized gap in literature when working with interpreters or translators in social science research. The use of a postcolonial reflection in the design and application of the research enabled greater reflection on issues regarding positionality, representation, access to participants, interpretation of others' voices, and the use of interpreters and participants in the production of data. Literature that discusses issues of triple subjectivity and three-way production of data brought to the fore an acknowledgement that the researcher, participants, and interpreters have a role to play in research design, and collection and presentation of interpreted empirical material.

From a practical field research standpoint, the qualitative methods adopted in the research demonstrates how it is possible to face some of the challenges relating to multiple (intersubjective) accounts when translation is used. For instance, investing in trained and engaged interpreters (research assistants), promoting best practice such as the use of pilot interviews, and capturing voices of participants to be used in questionnaire design helps to mitigate challenges related to bias, power relations, translation, and representation. Furthermore, working with research assistants and participants to explore varied lived experiences of those embedded in a particular social and political context provides the principal researcher with rich material that incorporates informed views and interpretations of all those active in the research.

The approach discussed in this paper enables a researcher to incorporate marginalized voices by critiquing imaginations of others, giving voice to all (including subalterns), and reflecting more deeply on positionalities and representations of others. It provides space to acknowledge inherent shortcomings when attempting to interpret and present marginalized voices and intersubjective accounts, and recognize power relations between the researcher, participants, 
and interpreters. However, it also promotes a way to strengthen the validity of research by ensuring all participants are active in the research process and generation of the qualitative material.

\section{References}

Adamson, J. and Donovan, J.L. (2002) 'Research in Black and White', Qualitative Health Research, 12, (6), pp. 816-825

Baker, N.G. (1981) 'Social work through an interpreter', Social Work, September, 26 (5), pp. 391-397

Baxter, J. and Eyles, J. (1997) 'Evaluating qualitative research in social geography: establishing 'rigour' in interview analysis', Transactions of the Institute of British Geographers, 22, 4, pp. 505-525.

Bondy, C. (2012) 'How did I get here? The social process of accessing field sites', , 13, (5), pp. 578-590

Bryman, A. (2008) Social research methods. Oxford; New York: Oxford University Press.

Cook, I. and Crang, M. (1995) Doing ethnographies. Norwich, England: Institute of British Geographers.

Crang, M. and Cook, I. (2007) Doing ethnographies. London: Sage.

Edwards, R. (1998) 'A critical examination of the use of interpreters in the qualitative research process', Journal of Ethnic and Migration Studies, 24, (2), pp. 197-208

Ergun, A. and Erdemir, A. (2010) 'Negotiating Insider and Outsider Identities in the Field: “Insider” in a Foreign Land; “Outsider” in One’s Own Land’ Field Methods, 22 (1), pp. $16-38$

Fathi, M. (2013) 'Dialogical and Transversal Translation: Trespassing Cultural Boundaries and Making the Self through Language' Narrative Works: Issues, Investigations and Interventions 3 (2), pp. 54-71

Flick, U. (2009) An introduction to qualitative research. Los Angeles; London: Sage.

FLO (2009) A Charter of Fair Trade Principles. Available at: http://www.fairtrade. net/fileadmin/user_upload/content/2009/about_us/documents/Fair_Trade_Charter.pdf (Accessed: 15th September 2009).

Freed, A.O. (1988) 'Interviewing Through An Interpreter', Social Work, July-August, 33 (4), pp. 315-319 
Fontana, A. and Frey, J. H. (2008) 'The Interview', in Denzin, N. K. and Lincoln, Y. S.(eds) Collecting and Interpreting Qualitative Materials. Sage, Thousand Oaks, CA, pp. 115160

Guha, R. (1982) Subaltern studies: writings on South Asian history and society. Delhi; New York: Oxford University Press.

Haraway, D. (1988) 'Situated Knowledges: The Science Question in Feminism and the Privilege of Partial Perspective', Feminist Studies, 14, (3), pp. 575-599.

Herod, A. (1999) 'Reflections on interviewing foreign elites: praxis, positionality, validity, and the cult of the insider', Geoforum, 30, (4), pp. 313-327.

Hoogvelt, A. M. M. (1997) Globalisation and the postcolonial world: the new political economy of development. Houndmills, England: Macmillan.

Hyman I, Guruge, S. and Mason, R. (2008) 'The impact of migration on marital relationships: a study of Ethiopian immigrants in Toronto'. Journal of Comparative Family Studies 39(2), pp. 149-163.

Kindon, S. L., Pain, R. and Kesby, M. (2007) Participatory action research approaches and methods: connecting people, participation, and place. Milton Park, Abingdon, Oxon; New York: Routledge.

Knight G.P., Roosa M.W. and Umaña-Taylor A.J. (2009) Studying Ethnic Minority and Economically Disadvantaged Populations. Methodological Challenges and Best Practices. Washington, DC: American Psychological Association.

Lacey, S. (2009) Beyond a Fair Price: The Co-operative movement and Fair Trade. Manchester: Co-operative College (Paper 14).

Limb, M. and Dwyer, C. (2001) Qualitative methodologies for geographers. London: Arnold.

Littig, B. and Pöchhacker, F. (2014) 'Socio-Translational Collaboration in Qualitative Inquiry: The Case of Expert Interviews’ Qualitative Inquiry 20 (9), pp. 1085-1095

McEwan, C. (2008) Postcolonialism and Development. London: Routledge.

Mercer, C., Mohan, G. and Power, M. (2003) 'Towards a critical political geography of African development', Geoforum, 34, 4, pp. 419-436.

Mohan, G. (1999) 'Not so Distant, Not so Strange: the Personal and the Political in Participatory Research', Ethics, Place and Environment, 2, (1), pp. 41-54. 
Mohan, G. (2001) 'Post-colonialism, development geography, and African politics', AAG. New York, March 2001.

Moser, S. (2008) 'Personality: a new positionality?' Area, 40, (3), pp. 383-392.

Munck, R. (1999) 'Deconstructing Development Discourses: of Impasses, Alternatives and Politics', in Munck, R. and O'Hearn, D.(eds) Critical development theory : contributions to a new paradigm, Zed Books, London, pp. 195-209.

Murray, C.D. and Wynne, J. (2001) 'Researching community, work and family with an interpreter’. Community, Work, Family 4, 2, pp. 158-171.

Narin, K., Munro, J. and Smith, A. B. (2005) 'A counter narrative of a failed interview', Qualitative Research, 5, (2), pp. 221-244.

Nelson, V. and Pound, B. (2009) The Last Ten Years: A Comprehensive Review of the Literature on the Impact of Fairtrade. Greenwich: NRI

Pain, R. (2001) Introducing social geographies. London: Arnold.

Power, M. (2003) Rethinking development geographies. London: Routledge.

Raghuram, P. and Madge, C. (2006) 'Towards a method for postcolonial development geography? Possibilities and challenges', Singapore Journal of Tropical Geography, 27, 3, pp. 270-288.

Raynolds, L. T., Murray, D. and Wilkinson, J. (2007) Fair Trade. London and New York: Routledge.

Reeves, C.L. (2010) ‘A difficult negotiation: fieldwork relations with gatekeepers', Qualitative Research, 10, 3, pp. 315-331

Rose, G. (1997) 'Situating knowledges: positionality, reflexivities and other tactics ', Progress in Human Geography, 21, (3), pp. 305-320.

Seale, C. (2012) Researching Society and Culture. London: Sage.

Shklarov, S. (2007) 'Double Vision Uncertainty: The Bilingual Researcher and the Ethics of Cross-Language Research’, Qualitative Health Research, 17, (4), pp. 529-538

Skelton, T. (2001) 'Cross-cultural research: issues of power, positionality, and 'race", in Limb, M. and Dwyer, C.(eds) Qualitative methodologies for geographers, Arnold, London, pp. $87-100$..

Spivak, G. C. (1988) In other worlds: essays in cultural politics. New York: Routledge. 
Spivak, G. C. (1999) A critique of postcolonial reason: toward a history of the vanishing present. Cambridge, Mass.: Harvard University Press.

Squires, A. (2009) 'Methodological challenges in cross-language qualitative research: A research review’, International Journal of Nursing Studies, 46, (2), pp. 277-287

Temple, B. and Edwards, R. (2002) 'Interpreters/Translators and Cross-Language Research: Reflexivity and Border Crossings', International Journal of Qualitative Methods, 1, (2), pp. 1-12.

Temple, B. and Young, A. (2004) 'Qualitative research and translation dilemmas', Qualitative Research, 4, (2), pp. 161-178.

Townsend, J. G. (1995) Women's voices from the rainforest. London; New York: Routledge.

Valentine, G. (2002) People like us: negotiating sameness and difference in the research process. In, Pamela Moss, (ed.), Feminist Geography in Practice. Oxford: Blackwell, pp. 116-126

Williamson, D.L., Choi, J., Charchuk, M., Rempel, G.R., Pitre,N., Breitkreuz, R.S., Kushner, K.E. (2011) 'Interpreter-Facilitated Cross-Language Interviews: Explicating Processes and Assessing Validity', Qualitative Research, 11, (4), pp. 381-394 